\title{
Dosage prediction of chloroquine and ritonavir-boosted lopinavir for COVID-19 treatment: A physiologically-based pharmacokinetic (PBPK) modelling
}

\author{
Teerachat Saeheng ${ }^{1}$, Kesara Na-Bangchang ${ }^{2}$, Rajith Rajoli ${ }^{3}$, Marco Siccardi ${ }^{3}$, and Juntra \\ Karbwang ${ }^{4}$ \\ ${ }^{1}$ Nagasaki University School of Medicine Graduate School of Biomedical Sciences \\ ${ }^{2}$ Center of Excellence in Pharmacology and Molecular Biology of Malaria and \\ Cholangiocarcinoma, Chulabhorn International College, Thammasat University \\ ${ }^{3}$ University of Liverpool Institute of Translational Medicine \\ ${ }^{4} \mathrm{NEKKEN}$
}

May 5, 2020

\begin{abstract}
Abstract Background and Purpose: The 2019 novel coronavirus (COVID-19) has been spread out since December 2019 from China to 29 countries. No effective treatment is currently available, although the combination regimen of the antiretroviral drugs- lopinavir/ritonavir (LPV/r), with other antiviral drugs have been using, but the evidences are limited. A recent in vitro study showed that chloroquine could inhibit COVID-19 to cells, and enhance antiviral efficacy. This study aimed to predict the optimal dose regimens of LPV/r, and chloroquine in combination as a potential treatment of COVID-19 infection, using the physiologically-based pharmacokinetic (PBPK) modelling. Experimental approach: The whole PBPK models were constructed. The predicted plasma drug concentrations were compared with the published clinical data. The validated models were used to predict optimal dosage regimens of LPV/r, and chloroquine co-administration. The optimal dose regimen was determined based on the efficacy, and toxicity reported in the published data. Key Results: The average errors of the predicted values were within $30 \%$ of the observed data. The proposed optimal dosage regimen is the once-daily dose of $800 / 200 \mathrm{mg} \mathrm{LPV} / \mathrm{r}$ co-administered with chloroquine at a loading dose of $1,000 \mathrm{mg}$, followed by twice-daily dose of $500 \mathrm{mg}$ for 8 doses on the second day, and the twice-daily dose of $400 \mathrm{mg}$ for 18 doses. Conclusion and Implications: PBPK modelling successfully predicted pharmacokinetic profiles within an acceptable range of errors. The study provides a focus for clinical studies to confirm the efficacy of the proposed dosage regimen as a novel treatment for COVID-19 infection.
\end{abstract}

\section{Introduction}

The 2019 novel coronavirus (COVID-19) is becoming a serious global health catastrophe with 80,248 confirmed cases, 27,754 recovered cases, and 2,706 deaths reported as of February 25, 2020 (Wolrdometer, 2020). Currently, there remain 49,788 infected patients, of which 40,573 cases are with mild symptoms, and 9,215 cases are those with serious conditions (Wolrdometer, 2020). Since the COVID-19 is a novel coronavirus, no specific effective treatment is currently available. Available drug regimens that can potentially represent therapeutic options for infected patients are the combination of antiretroviral drugs (lopinavir/ritonavir) as well as other antiviral medications (ganciclovir, and oseltamivir)(Chen et al., 2020; Huang et al., 2020). The use of lopinavir/ritonavir (LPV/r) for the treatment of COVID-19 was based on its efficacy against SARS$\mathrm{CoV}$ (Chu et al., 2004), and the similarity between the COVID-19 genome with the human SARS-CoV(Zhu et al., 2020). However, the evidence to support the efficacy, and optimal dosage regimen of these drugs is limited. Recent data suggest that the recovery rate of currently used drug combination is less than $20 \%$ 
(Chen et al., 2020; Huang et al., 2020). There is an urgent need to look for other treatment regimens to broad the therapeutic options for COVID-19 to control the emerging epidemic. A recent in vitro study showed that chloroquine (an antimalarial) could inhibit COVID-19 entry, and post-entry to the infected cells, and enhance antiretroviral drug efficacy(Wang et al., 2020). Furthermore, chloroquine has been shown to moderate host immunity, supporting its antiretroviral effect (Wang et al., 2020). The combination of LPV/r, and chloroquine could represent a promising drug regimen to treat COVID-19. However, the optimal dosage regimen(s) of chloroquine in combination with $\mathrm{LPV} / \mathrm{r}$ that would result in adequate plasma chloroquine concentrations has not been identified. Besides, the co-administration of chloroquine with ritonavir may pose the patients at risk of chloroquine toxicity (e.g ., retinopathy) due to the inhibitory effect of ritonavir on chloroquine metabolism (Projean et al., 2003; Yeh et al., 2006).

Physiologically-based pharmacokinetic (PBPK) modelling has been used successfully for dose optimization in various diseases (Sager, Yu, Ragueneau-Majlessi, \& Isoherranen, 2015). PBPK modelling is accepted by regulatory agencies including the United States Food and Drug Administration (US FDA), and the European Medicine Agencies (EMA) to be applied as a tool to support drug regulatory submission a prediction of drug-drug interactions (DDIs) (Shebley et al., 2018). ${ }^{10}$ The present study aimed to predict optimal dosage regimens for the co-administration of $\mathrm{LPV} / \mathrm{r}$, and chloroquine for the treatment of COVID-19 using PBPK modelling.

\section{Methods}

\subsection{Model construction}

The whole PBPK models for LPV/r, and chloroquine were constructed based on the previously published articles (Saeheng, Na-Bangchang, Siccardi, Rajoli, \& Karbwang, 2019; Siccardi, 2015) using Simbiology@) (version 5.8.2), the product of MATLABß) (version 2019a) (MathWorks, Natick, MA, USA). The physicochemical, and biochemical properties (model parameters) of each drug were collected from the published articles (Table S1) (Ernest, Hall, \& Jones, 2005; Koudriakova et al., 1998; Olafuyi \& Badhan, 2019; Patel, Mandava, Gokulgandhi, Pal, \& Mitra, 2014; Saeheng et al., 2019; Wagner et al., 2017; Xu, Vela, Shi, Marroum, \& Gao, 2017; Zhang et al., 2012). Model assumptions included blood-flow limited model, immediate drug dissolution, absence of drug absorption in the stomach and large intestine, and absence of enterohepatic recirculation. The hepatic fraction of metabolism by cytochrome P450 (CYP) 3A4 ( $\left.\mathrm{f}_{\mathrm{m}, \text { CYP3A4 }}\right)$, and the fraction of metabolism by CYP2D6 ( $\left.\mathrm{f}_{\mathrm{m}, \mathrm{CYP} 2 \mathrm{D} 6}\right)$ were assumed to be 0.61 , and 0.39 , respectively (Projean et al., 2003).

\subsection{Model verification}

Four published clinical articles were used for model validation (Eron et al., 2004; Hsu et al., 1997; Mzayek et al., 2007; Na-Bangchang, Limpaibul, Thanavibul, Tan-Ariya, \& Karbwang, 1994). The absolute averagefolding errors (AAFEs) (the comparison between the predicted results against clinical published data) were calculated to determine model accuracy. AAFEs value below 2 is considered as acceptable following recent publication (Saeheng, Na-Bangchang, \& Karbwang, 2018). AAFEs can be calculated using the following equation:

$$
\text { AAFEs }=10^{\frac{\sum_{i=1}^{n}\left|\log \frac{\text { prediction }}{\text { observation }}\right|}{n}}
$$

Where $\mathrm{n}$ is the number of samples; the prediction and observation are simulated results, and observed clinical data, respectively.

\subsection{Sensitivity analysis}

The sensitivity analysis (sensitivity coefficient) was performed to determine the effect of model parameters on the area under the curve (AUC) following the standard regimen of chloroquine (once-daily dose of $250 \mathrm{mg}$ for 14 days). The model parameters for sensitivity analysis were absorption rate $\left(\mathrm{K}_{\mathrm{a}}\right)$, fraction of unbound 
$\operatorname{drug}\left(f_{\mathrm{u}}\right)$, liver weight, blood-to-plasma ratio $\left(\mathrm{R}_{\mathrm{bp}}\right), \mathrm{f}_{\mathrm{m}}$, CYP3A4, and $\mathrm{f}_{\mathrm{m}}$, CYP2D6. The mathematical equation is as follow:

Sensitivity coefficient $=\% \mathrm{Y} / \% \mathrm{X}$

Where $\% \mathrm{Y}$, and $\% \mathrm{X}$ is the percent change of the $\mathrm{AUC}_{336-360 \mathrm{~h}}$, and the percent change of model parameter, respectively.

\subsection{Single drug simulation}

One hundred virtual population (100 males, aged 30 to 60 years in the fasting state) were simulated. The period of simulation time was based on the maximal admission time of patients in the hospital (14 days) (Chen et al., 2020). The standard dose regimens of chloroquine for rheumatoid arthritis treatment (once-daily dose of $250 \mathrm{mg}$ ) were simulated (da Mota et al., 2013). ${ }^{19} \mathrm{In}$ addition, the twice-daily regimen of 400/100 $\mathrm{mg}$ $\mathrm{LPV} / \mathrm{r}$ (based on the regimen used for COVID-19 treatment) were simulated (Chen et al., 2020).

\subsection{Estimation of chloroquine toxicity based on the maximum dosage used in clinical trials}

The dose of $20 \mathrm{mg} / \mathrm{kg}$ body weight/day (total dose of $1,200 \mathrm{mg} /$ day for an average $60 \mathrm{~kg}$ body weight) of a once-daily regimen of chloroquine for 6 consecutive weeks (Furst et al., 1999) used for simulations was based on clinically published data. Maximum plasma concentration $\left(\mathrm{C}_{\max }\right)$ of unbound chloroquine was used as the pharmacokinetic parameter for chloroquine toxicity.

\subsection{Simulations of the plasma concentration-time profile of chloroquine when co-administered with lopinavir $(\mathrm{LPV} / \mathrm{r})$}

Simulation based on standard drug-drug interactions (DDIs) study approach: multiple doses of the twicedaily regimen of $\mathrm{LPV} / \mathrm{r}(400 / 100 \mathrm{mg})$ for 15 consecutive days with the co-administration of a single dose of $250 \mathrm{mg}$ chloroquine on day 15 were simulated.

Simulation based on actual clinical use approach: multiple doses of the twice-daily regimen of LPV/r (400/100 $\mathrm{mg}$ ) with the co-administration of the once-daily regimen of $250 \mathrm{mg}$ chloroquine given for 14 days were simulated.

AUC ratios (the comparison of chloroquine AUC administration alone, and the chloroquine AUC coadministered with LPV/r) were calculated to determine the effect of $\mathrm{LPV} / \mathrm{r}$ on chloroquine pharmacokinetics. Dosage regimens of $\mathrm{LPV} / \mathrm{r}$ for simulation (total=14 consecutive days) were: (i) a twice-daily regimen of 400/100 mg, and (ii) a once-daily regimen of 800/100 mg.

\subsection{Prediction of the optimal dose regimens for chloroquine and lopinavir}

The optimal dose regimen of lopinavir was determined based on the previously reported cytopathic effect on SARS-CoV, and maximum dose used in the published clinical trial, i.e., unbound trough plasma concentration $\left(\mathrm{C}_{\text {trough }}\right)>0.04 \mathrm{mg} \mathrm{l}^{-1}$ (Chu et al., 2004). The optimal dose regimen of chloroquine was determined based on the reported $50 \%$ effective concentration of COVID-19 (EC E0 $_{50} 1.13 \mu \mathrm{M}$ or $0.36 \mathrm{mg} \mathrm{l}^{-1}$ ) (Wang et al., 2020), or unbound $\mathrm{C}_{\text {trough }}$ at 24 hours, or 12 hours, or 8 hours $>0.36 \mathrm{mg} \mathrm{l}^{-1}$. The maximum doses of chloroquine, and LPV/r used for simulations were $20 \mathrm{mg} \mathrm{kg}^{-1}$ body weight day ${ }^{-1}$ (Furst et al., 1999), and $800 / 200 \mathrm{mg} \mathrm{day}^{-1}$ (Eron et al., 2004), respectively. The predicted pharmacokinetic parameters were reported as mean \pm standard deviation (SD).

\section{Results}

The overall AAFEs was 1.25 (ranged: 1.08-1.59) (Eron et al., 2004; Hsu et al., 1997; Mzayek et al., 2007; Na-Bangchang et al., 1994). The AAFEs for ritonavir, lopinavir (LPV/r), and chloroquine were 1.30 (Hsu et al., 1997), 1.17 (Eron et al., 2004) and 1.27 (Mzayek et al., 2007; Na-Bangchang et al., 1994), respectively. All AAFEs values were within the accepted ranges (Table $S 2$ ). Sensitivity coefficients for $K_{a}, f_{u}, R_{b p}, f_{m}$, CYP3A4, and $\mathrm{f}_{\mathrm{m}, \text { CYP2D } 6}$ were $+0.13,-0.90,+0.06,-0.50$, and +1.34 , respectively. All sensitivity coefficients except for $\mathrm{f}_{\mathrm{m}, \mathrm{CYP} 2 \mathrm{D} 6}$ were less than one, indicating no significant effects of the model parameters on the AUC 
values. Although $\mathrm{f}_{\mathrm{m}, \mathrm{CYP} 2 \mathrm{D} 6}$ was greater than one, this value was assumed based on the intrinsic clearance of chloroquine from the vitro studies. ${ }^{7}$ All parameters were within the accepted ranges, indicating model reliability.

\subsection{Simulations of plasma concentration-time profiles of chloroquine and lopinavir (LPV/r) when administered alone}

Chloroquine: The average unbound $\mathrm{C}_{\text {trough }}$ at 24 hours following the standard once-daily regimen of 250 $\mathrm{mg}$ was $0.06 \pm 0.01 \mathrm{mg} \mathrm{l}^{-1}$. This dose regimen could not provide drug concentrations over the $\mathrm{EC}_{50}$ level. Time to reach $\mathrm{EC}_{50}$ was 7 days. Subsequent simulation using the once-daily dose of $500 \mathrm{mg}$ resulted in the average values of unbound $\mathrm{C}_{\text {trough }}$ at 24 hours, and the time to reach $\mathrm{EC}_{50}$ of $0.13 \pm 0.02 \mathrm{mg} \mathrm{l}^{-1}$, and 7 days, respectively.

Lopinavir $(\mathrm{LPV} / \mathrm{r})$ : The average unbound $\mathrm{C}_{\text {trough }}$ at 24 hours following the standard twice-daily regimen of $\mathrm{LPV} / \mathrm{r}(400 / 100 \mathrm{mg})$ was $0.0341 \pm 0.008 \mathrm{mg} \mathrm{l}^{-1}$ (figure 1). Subsequent simulation using the once-daily dose regimen of 800/100 $\mathrm{mg}$ resulted in the average unbound $\mathrm{C}_{\text {trough }}$ at 24 hours of $0.0468 \pm 0.0163 \mathrm{mg} \mathrm{l}^{-1}$ (figure $1)$.

\subsection{Estimation of chloroquine toxicity based on the maximum dose regimen used in clinical trials}

The average unbound $\mathrm{C}_{\max }$ as the level of chloroquine toxicity estimated based on the maximum dose regimen used in clinical trials was $2.36 \pm 0.55 \mathrm{mg} \mathrm{l}^{-1}$.

3.3 Simulations of the plasma concentration-time profile of chloroquine when co-administered with lopinavir $(\mathrm{LPV} / \mathrm{r})$

Simulation based on standard DDIs study approach: The recommended dosage of chloroquine for rheumatoid arthritis treatment (250 mg once daily) in combination with LPV/r (400/100 mg twice-daily dose) resulted in a 1.45-fold increase in the AUC for chloroquine indicating a significant but weak DDI. The average unbound $\mathrm{C}_{\text {trough }}$ at 24 hours, and the average unbound $\mathrm{C}_{\max }$ were $0.10 \pm 0.01$, and $0.30 \pm 0.05 \mathrm{mg} \mathrm{l}^{-1}$, respectively.

Simulation based on actual clinical use approach: The recommended once-daily dose of $250 \mathrm{mg}$ chloroquine co-administered with $\mathrm{LPV} / \mathrm{r}(400 / 100 \mathrm{mg}$ twice-daily dose) provided a 1.50-fold increase in the AUC of chloroquine $(\mathrm{AUCR}=1.50)$. The average unbound $\mathrm{C}_{\text {trough }}$ at 24 hours, and the average unbound $\mathrm{C}_{\max }$ were $0.11 \pm 0.03 \mathrm{mg} \mathrm{l}^{-1}$, and $1.82 \pm 0.15 \mathrm{mg} \mathrm{l}^{-1}$, respectively. The time to reach $\mathrm{EC}_{50}$ was 5 days. The weak DDI (AUCR $>1.25$ to $<2$ fold) resulted in the lower average unbound $\mathrm{C}_{\text {trough }}$ at 24 hours than the $\mathrm{EC}_{50}$, and the lower unbound $\mathrm{C}_{\max }$ than the toxicity level, and thus significant dose reduction is probably not requiring. Subsequent simulation of the once-daily regimen of $250 \mathrm{mg}$ chloroquine co-administered with LPV/r (800/100 $\mathrm{mg}$ once-daily dose) resulted in the average unbound $\mathrm{C}_{\text {trough }}$ at 24 hours, and unbound $\mathrm{C}_{\max }$ of $0.11 \pm 0.02 \mathrm{mg}$ $\mathrm{l}^{-1}$, and $0.80 \pm 0.15 \mathrm{mg} \mathrm{l}^{-1}$, respectively. A $500 \mathrm{mg}$ once-daily dose of chloroquine co-administered with $\mathrm{LPV} / \mathrm{r}$ (400/100 mg once-daily dose was simulated. The average unbound $\mathrm{C}_{\text {trough }}$ at 24 hours, and unbound $\mathrm{C}_{\max }$ were $0.22 \pm 0.04 \mathrm{mg} \mathrm{l}^{-1}, 1.62 \pm 0.27 \mathrm{mg} \mathrm{l}^{-1}$, respectively. Besides, the average unbound $\mathrm{C}_{\text {trough }}$ at 24 hours, and unbound $\mathrm{C}_{\max }$ following the once-daily regimen of $500 \mathrm{mg}$ chloroquine co-administered with $\mathrm{LPV} / \mathrm{r}(800 / 100$ mg once-daily dose) were $0.22 \pm 0.05 \mathrm{mg} \mathrm{l}^{-1}$, and $1.62 \pm 0.30 \mathrm{mg} \mathrm{l}^{-1}$, respectively. None of the current clinically used dosage regimens of chloroquine provided unbound $\mathrm{C}_{\text {trough }}$ above the $\mathrm{EC}_{50}$ level.

Subsequent simulations were performed to identify the potential dose regimen(s) of chloroquine that could result in chloroquine plasma concentrations above the $\mathrm{EC}_{50}$ level. Chloroquine at the twice-daily regimen of $500 \mathrm{mg}$ co-administered with 400/100 mg twice-daily dose, or 800/200 mg once-daily dose LPV/r provided adequate unbound $\mathrm{C}_{\max }$, but insufficient unbound $\mathrm{C}_{\text {trough }}$ at 24 hours (figure 2 (regimen $\mathrm{A}$ ), and 3 (regimen $\mathrm{A})$ ). Time to reach $\mathrm{EC}_{50}$ for the 400/100 $\mathrm{mg}$ twice-daily dose, and 800/100 $\mathrm{mg}$ once-daily dose LPV/r dose regimen was 48 hours. Chloroquine at the dose of $400 \mathrm{mg}$ given three times a day in combination with 400/100 mg twice-daily dose (figure 2 (regimen B)) or 800/200 mg once-daily dose LPV/r (figure 3 (regimen $\mathrm{B}$ )) provided toxic level of unbound $\mathrm{C}_{\max }$, and inadequate unbound $\mathrm{C}_{\text {trough }}$ at 8 hours. This regimen, however, reduced the time to reach $\mathrm{EC}_{50}$ to 24 hours. The pharmacokinetic parameters of chloroquine following other 
dose regimens (i.e., a once-daily dose of $1000 \mathrm{mg}$, a loading dose of $1,000 \mathrm{mg}$, followed by twice-daily dose of $500 \mathrm{mg}$, and a loading dose of 1,000 $\mathrm{mg}$, followed by twice-daily dose of $500 \mathrm{mg}$ for 8 doses, and twice-daily dose of $400 \mathrm{mg}$ for 18 doses) are shown in figure 2 (co-administered with 400/100 $\mathrm{mg} \mathrm{LPV} / \mathrm{r}$ regimen C,D, E, respectively), and figure 3 (co-administered with $800 / 200 \mathrm{mg} \mathrm{LPV} / \mathrm{r}$ regimen C, D, E, respectively). All three doses of chloroquine regimens provided unbound $\mathrm{C}_{\text {trough }}$ above the $\mathrm{EC}_{50}$ level within 24 hours.

\section{Discussion and conclusion}

Results of the current study suggest that PBPK modelling successfully predicted plasma concentration-time profiles of chloroquine and lopinavir $(\mathrm{LPV} / \mathrm{r}$ ) when given alone, or in combination. The results suggest that there is a weak but potentially significant DDIs between chloroquine, and LPV/r. Using PBPK modelling can guide the selection of appropriate dose regimens in terms of both efficacy, and safety. Simulations of several dosage regimens of chloroquine administration alone, and when co-administered with lopinavir (LPV/r) offer potential dose optimization strategies for the treatment regimen for COVID-19 infected patients.

\subsection{LPV/r alone for the treatment of COVID-19 infection}

The simulation of LPV/r at the dose of 400/100 mg twice-daily dose (currently used to treat COVID-19) may not be an optimal dose regimen due to insufficient unbound $\mathrm{C}_{\text {trough }}$ at 24 hours (figure 1 (regimen A)). The $800 / 200 \mathrm{mg} \mathrm{LPV} / \mathrm{r}$ once-daily dose may be a better option to ensure the unbound $\mathrm{C}_{\text {trough }}$ at 24 hours above $0.04 \mathrm{mg} \mathrm{l}^{-1}$ (figure 1 (regimen B)). ${ }^{4}$ This may explain the recovery rate of less than $20 \%$ of the currently used 400/100 mg twice-daily dose LPV/r even when used in combination with other antiretroviral drugs (Chen et al., 2020; Huang et al., 2020). The successful treatment reported in some patients (Chen et al., 2020) treated with 400/100 mg twice-daily dose LPV/r could be explained by a relatively higher sensitivity of the COVID-19 to lopinavir compared with SARS-CoV.

\subsection{Chloroquine alone for the treatment of COVID-19 infection}

The initial once-daily dose of $250 \mathrm{mg}$ chloroquine provided adequate plasma concentration-time profiles to achieve the therapeutic effect $\left(\mathrm{EC}_{50}\right)$ for COVID-19 on day 7 . Nevertheless, the unbound $\mathrm{C}_{\text {trough }}$ at 24 hours was not sufficient to exert inhibitory effect $\left(\mathrm{EC}_{50}\right)$ on the virus. This regimen is, therefore, not appropriate for the treatment of COVID-19 infection. This finding is in accordance with that was reported by Wang and colleagues $^{6}$, of which the $\mathrm{EC}_{50}$ could not be achieved with the drug concentration delivered following the once-daily dose regimen of $250 \mathrm{mg}$ chloroquine (for 28 days) in rheumatoid patients. Simulation of chloroquine $500 \mathrm{mg}$ once-daily dose also did not provide adequate the unbound $\mathrm{C}_{\text {trough }}$ at 24 hours to exert inhibitory effect $\left(\mathrm{EC}_{50}\right)$ on the virus. This finding is in contrast with Wang and colleagues' proposal that the concentration achieved following the once-daily dose regimen of $500 \mathrm{mg}$ chloroquine could be sufficient to inhibit the entry of the virus into host cells (Wang et al., 2020). This could be due to the fact that the reported $500 \mathrm{mg}$-plasma concentration profiles were not actual observed clinical data, but the extrapolation from the once-daily dose regimen of $250 \mathrm{mg}$ in rheumatoid patients.

\subsection{Chloroquine and LPV $/ \mathrm{r}$ combination for the treatment of COVID-19 infection}

Based on the results of the simulation, co-administration of LPV/r (400/100 mg twice-daily dose, or 800/200 $\mathrm{mg}$ once-daily dose), and once-daily regimen of $250 \mathrm{mg}$, and $500 \mathrm{mg}$ are not optimal due to inadequate concentration-time profiles of chloroquine above the $\mathrm{EC}_{50}$ level $\left(\mathrm{C}_{\text {trough }}\right)$. Increasing chloroquine dose to reach $\mathrm{EC}_{50}$ should offer better clinical benefits in term of treatment efficacy. Based on the simulations, only one chloroquine dosage regimen provided adequate plasma drug concentrations for preventing viral entry, and below the toxic levels i.e., a 1,000 $\mathrm{mg}$ loading dose, followed by the twice-daily dose of $500 \mathrm{mg}$ for 8 doses on the second day, and the twice-daily dose of $400 \mathrm{mg}$ for 18 doses, co-administered with once-daily dose of 400/100 mg, and 800/200 mg LPV/r (figure 2 (regimen E), and figure 3 (regimen E)). The regimen offered chloroquine unbound $\mathrm{C}_{\text {trough }}$ of higher than $\mathrm{EC}_{50}$. Although plasma chloroquine concentrations following both regimens of LPV/r were similar, the desirable dose of LPV/r should be 800/200 mg once-daily dose to ensure sufficient cytopathic effect at 24 hours (Chu et al., 2004). The results of this study provide a focus for further clinical studies to confirm this proposed regimen. 
Although other two regimens also provided adequate plasma concentration-time profiles for COVID-19 infection, the unbound $\mathrm{C}_{\max }$ was over toxic level (figure 2 (regimen $\mathrm{C} \& \mathrm{D}$ ), and figure 3 (regimen C\&D)), therefore, is an inappropriate dosage.

The simulated once-daily dose regimen of chloroquine (i.e., $1000 \mathrm{mg}$ once-daily dose) may be desirable when considering the reduction of frequency of drug administration; this regimen however, provided unbound $\mathrm{C}_{\max }$ of chloroquine over the toxic level (figure 3 (regimen $\mathrm{C}$ )).

Apart from efficacy, chloroquine-induced irreversible retinopathy is also of great concern when used in combination with LPV $/ \mathrm{r}$. The reported threshold dose of chloroquine-induced retinopathy was $5 \cdot 1 \mathrm{mg} / \mathrm{kg} / \mathrm{day}$ (300 $\mathrm{mg}$ for the average body weight of $60 \mathrm{~kg}$ ) (Mackenzie, 1983). However, the retinopathy from chloroquine is due to the accumulation of chloroquine after long-term use for at least 5 years (Mackenzie, 1983). Based on the previous clinical study, the high dose of chloroquine $\left(20 \mathrm{mg} \mathrm{kg}^{-1}\right.$ body weight day ${ }^{-1}$, or total dose of 1,200 day $^{-1}$ for the average body weight of $60 \mathrm{~kg}$ ) was safe for short-term treatment (6 weeks) (Furst et al., 1999). The chloroquine dose regimen used in our study is therefore, likely to be safe as the total duration of chloroquine administration for COVID-19 treatment is only 14 days.

One of the limitations of this study was that the contributions of P-glycoprotein transporter in the disposition of ritonavir, lopinavir, and chloroquine were not included in the model construction. Nevertheless, the inhibitory effect of ritonavir on P-glycoprotein may have a less significant impact on chloroquine disposition as chloroquine is a weak substrate of this transporter (Crowe, Ilett, Karunajeewa, Batty, \& Davis, 2006).

In summary, the developed PBPK models successfully predicted a potentially suitable regimen of chloroquine and LPV/r for COVID-19 infected patients. The proposed dosage regimen is the combination of the oncedaily dose of $800 / 200 \mathrm{mg} \mathrm{LPV} / \mathrm{r}$, in combination with chloroquine at a loading dose of 1,000 $\mathrm{mg}(16.67 \mathrm{mg}$ $\mathrm{kg}^{-1}$ body weight day ${ }^{-1}$ ), followed by twice-daily $500 \mathrm{mg}$ for 8 doses on the second day, and twice-daily 400 $\mathrm{mg}$ for 18 doses. The total duration of treatment is 14 days. The simulated results in this study represent an advanced framework to rationalize the selection of dose regimens to fight against this COVID-19 infection outbreak. The study provides a focus for further clinical studies to confirm the efficacy of the proposed dosage regimen as a novel treatment for COVID-19 infection.

\section{ACKNOWLEDGEMENTS}

T.S. is a recipient of the Nagasaki University Special Research Student Scholarship. J.K. is the recipient of Bualuang ASEAN Chair Professors and Center of Excellence in Pharmacology and Molecular Biology of Malaria and Cholangiocarcinoma.

\section{AUTHOR CONTRIBUTIONS}

J.K., K.N., and T.S. designed the study. M.S., R.K.R., and T.S. collected the data. M.S., R.K.R., and T.S. performed research and analysis. T.S. drafted the manuscript. M.S., and R.K.R. revised manuscript. J.K., and K.N. were responsible for the critical revision of the manuscript. All authors approved the final version.

\section{CONFLICT OF INTEREST}

All authors declare no competing interests.

\section{What is already known}

- Chloroquine exhibited anti-COVID-19 activity in vitro study.

- Lopinavir (ritonavir-boosted lopinavir or LPV/r) showed treatment efficacy for COVID-19.

\section{What this study adds}

- The proposed dosage regimen of $\mathrm{LPV} / \mathrm{r}$ was $800 / 100 \mathrm{mg}$ once-daily regimen for 14 consecutive days.

- Chloroquine dose (mg) was 1000 loading dose, 500 twice-daily (8 doses), 400 twice-daily (18 doses).

What is the clinical significance 
This study provided an alternative promising dosage regimen to fight against COVID-19 in current outbreak.

\section{REFERENCES}

Chen, N., Zhou, M., Dong, X., Qu, J., Gong, F., Han, Y., . . Zhang, L. (2020). Epidemiological and clinical characteristics of 99 cases of 2019 novel coronavirus pneumonia in Wuhan, China: a descriptive study.Lancet, 395 (10223), 507-513. doi:10.1016/S0140-6736(20)30211-7

Chu, C. M., Cheng, V. C., Hung, I. F., Wong, M. M., Chan, K. H., Chan, K. S., . . Group, H. U. S. S. (2004). Role of lopinavir/ritonavir in the treatment of SARS: initial virological and clinical findings. Thorax, 59 (3), 252-256. doi:10.1136/thorax.2003.012658

Crowe, A., Ilett, K. F., Karunajeewa, H. A., Batty, K. T., \& Davis, T. M. (2006). Role of P glycoprotein in absorption of novel antimalarial drugs. Antimicrob Agents Chemother, 50 (10), 3504-3506. doi:10.1128/AAC.00708-06

da Mota, L. M. H., Cruz, B. A., Brenol, C. V., Pereira, I. A., Rezende-Fronza, L. S., Bertolo, M. B., . . . Pinheiro, G. D. C. (2013). Guidelines for the drug treatment of rheumatoid arthritis (vol 53, pg 158, 2013). Revista Brasileira De Reumatologia, 53 (3), 319-320. doi:Doi 10.1590/S0482-50042013000300013

Ernest, C. S., 2nd, Hall, S. D., \& Jones, D. R. (2005). Mechanism-based inactivation of CYP3A by HIV protease inhibitors. Journal of Pharmacology and Experimental Therapeutics, 312 (2), 583-591. doi:10.1124/jpet.104.075416

Eron, J. J., Feinberg, J., Kessler, H. A., Horowitz, H. W., Witt, M. D., Carpio, F. F., . . Sun, E. (2004). Once-daily versus twice-daily lopinavir/ritonavir in antiretroviral-naive HIV-positive patients: a 48-week randomized clinical trial. Journal of Infectious Diseases, 189 (2), 265-272. doi:10.1086/380799

Furst, D. E., Lindsley, H., Baethge, B., Botstein, G. R., Caldwell, J., Dietz, F., . . . Yocum, D. (1999). Dose-loading with hydroxychloroquine improves the rate of response in early, active rheumatoid arthritis: a randomized, double-blind six-week trial with eighteen-week extension.Arthritis Rheum, 42 (2), 357-365. doi:10.1002/1529-0131(199902)42:2<357::AID-ANR19>3.0.CO;2-J

Hsu, A., Granneman, G. R., Witt, G., Locke, C., Denissen, J., Molla, A., . . Leonard, J. M. (1997). Multipledose pharmacokinetics of ritonavir in human immunodeficiency virus-infected subjects. Antimicrob Agents Chemother, 41 (5), 898-905.

Huang, C., Wang, Y., Li, X., Ren, L., Zhao, J., Hu, Y., . . Cao, B. (2020). Clinical features of patients infected with 2019 novel coronavirus in Wuhan, China. Lancet, 395 (10223), 497-506. doi:10.1016/S01406736(20)30183-5

Koudriakova, T., Iatsimirskaia, E., Utkin, I., Gangl, E., Vouros, P., Storozhuk, E., . . . Gerber, N. (1998). Metabolism of the human immunodeficiency virus protease inhibitors indinavir and ritonavir by human intestinal microsomes and expressed cytochrome P4503A4/3A5: mechanism-based inactivation of cytochrome P4503A by ritonavir.Drug Metabolism and Disposition, 26 (6), 552-561.

Mackenzie, A. H. (1983). Dose refinements in long-term therapy of rheumatoid arthritis with antimalarials. Am J Med, 75 (1A), 40-45. doi:10.1016/0002-9343(83)91269-x

Mzayek, F., Deng, H., Mather, F. J., Wasilevich, E. C., Liu, H., Hadi, C. M., . . Krogstad, D. J. (2007). Randomized dose-ranging controlled trial of AQ-13, a candidate antimalarial, and chloroquine in healthy volunteers. PLoS Clin Trials, 2 (1), e6. doi:10.1371/journal.pctr.0020006

Na-Bangchang, K., Limpaibul, L., Thanavibul, A., Tan-Ariya, P., \& Karbwang, J. (1994). The pharmacokinetics of chloroquine in healthy Thai subjects and patients with Plasmodium vivax malaria. Br J Clin Pharmacol, 38 (3), 278-281. doi:10.1111/j.1365-2125.1994.tb04354.x

Olafuyi, O., \& Badhan, R. K. S. (2019). Dose Optimization of Chloroquine by Pharmacokinetic Modeling During Pregnancy for the Treatment of Zika Virus Infection. J Pharm Sci, 108 (1), 661-673. 
doi:10.1016/j.xphs.2018.10.056

Patel, M., Mandava, N., Gokulgandhi, M., Pal, D., \& Mitra, A. K. (2014). Amino Acid Prodrugs: An Approach to Improve the Absorption of HIV-1 Protease Inhibitor, Lopinavir. Pharmaceuticals (Basel), 7 (4), 433-452. doi:10.3390/ph7040433

Projean, D., Baune, B., Farinotti, R., Flinois, J. P., Beaune, P., Taburet, A. M., \& Ducharme, J. (2003). In vitro metabolism of chloroquine: Identification of CYP2C8, CYP3A4, and CYP2D6 as the main isoforms catalyzing N-desethylchloroquine formation. Drug Metabolism and Disposition, 31 (6), 748-754. doi:DOI 10.1124/dmd.31.6.748

Saeheng, T., Na-Bangchang, K., \& Karbwang, J. (2018). Utility of physiologically based pharmacokinetic (PBPK) modeling in oncology drug development and its accuracy: a systematic review. European Journal of Clinical Pharmacology, 74 (11), 1365-1376. doi:10.1007/s00228-018-2513-6

Saeheng, T., Na-Bangchang, K., Siccardi, M., Rajoli, R. K. R., \& Karbwang, J. (2019). PhysiologicallyBased Pharmacokinetic Modeling for Optimal Dosage Prediction of Quinine Coadministered With RitonavirBoosted Lopinavir. Clinical Pharmacology \& Therapeutics . doi:10.1002/cpt.1721

Sager, J. E., Yu, J., Ragueneau-Majlessi, I., \& Isoherranen, N. (2015). Physiologically Based Pharmacokinetic (PBPK) Modeling and Simulation Approaches: A Systematic Review of Published Models, Applications, and Model Verification. Drug Metabolism and Disposition, 43 (11), 1823-1837. doi:10.1124/dmd.115.065920

Shebley, M., Sandhu, P., Riedmaier, A. E., Jamei, M., Narayanan, R., Patel, A., . . Rowland, M. (2018). Physiologically Based Pharmacokinetic Model Qualification and Reporting Procedures for Regulatory Submissions: A Consortium Perspective. Clinical Pharmacology \& Therapeutics, 104 (1), 88-110. doi:10.1002/cpt.1013

Siccardi, M. R., M.;Rajoli, R.KR.; Dickinson, L.; Khoo, S.; Owen, A.; Back, D. (2015). In Silico Simulation of Interaction Between Rifampicin and Boosted Darunavir. Conference on retroviruses and opportunistic infections. Retrieved from http://www.croiconference.org/sessions/silico-simulation-interactionbetween-rifampicin-and-boosted-darunavir

Wagner, C., Zhao, P., Arya, V., Mullick, C., Struble, K., \& Au, S. (2017). Physiologically Based Pharmacokinetic Modeling for Predicting the Effect of Intrinsic and Extrinsic Factors on Darunavir or Lopinavir Exposure Coadministered With Ritonavir. Journal of Clinical Pharmacology, 57 (10), 1295-1304. doi:10.1002/jcph.936

Wang, M. L., Cao, R. Y., Zhang, L. K., Yang, X. L., Liu, J., Xu, M. Y., . . Xiao, G. F. (2020). Remdesivir and chloroquine effectively inhibit the recently emerged novel coronavirus (2019-nCoV) in vitro. Cell Research . doi:10.1038/s41422-020-0282-0

Wolrdometer. (2020). COVID-19 CORONAVIRUS OUTBREAK. Retrieved from https://www.worldometers.info/coronavirus/

Xu, H., Vela, S., Shi, Y., Marroum, P., \& Gao, P. (2017). In Vitro Characterization of Ritonavir Drug Products and Correlation to Human in Vivo Performance. Mol Pharm, 14 (11), 3801-3814. doi:10.1021/acs.molpharmaceut.7b00552

Yeh, R. F., Gaver, V. E., Patterson, K. B., Rezk, N. L., Baxter-Meheux, F., Blake, M. J., . . Kashuba, A. D. M. (2006). Lopinavir/ritonavir induces the hepatic activity of cytochrome P450 enzymes CYP2C9, CYP2C19, and CYP1A2 but inhibits the hepatic and intestinal activity of CYP3A as measured by a phenotyping drug cocktail in healthy volunteers. Jaids-Journal of Acquired Immune Deficiency Syndromes, 42 (1), 52-60.

Zhang, C., McIlleron, H., Ren, Y., van der Walt, J. S., Karlsson, M. O., Simonsson, U. S. H., \& Denti, P. (2012). Population pharmacokinetics of lopinavir and ritonavir in combination with rifampicin-based antitubercular treatment in HIV-infected children. Antiviral Therapy, 17 (1), 25-33. doi:10.3851/Imp1915

Zhu, N., Zhang, D., Wang, W., Li, X., Yang, B., Song, J., . . Research, T. (2020). A Novel Coronavirus from Patients with Pneumonia in China, 2019. N Engl J Med, 382 (8), 727-733. doi:10.1056/NEJMoa2001017 


\section{Figure legends}

Figure 1 The prediction of lopinavir (LPV/r) concentration-time profiles given twice daily (LPV/r: 400/100 $\mathrm{mg}$ ), or once daily (LPV/r: 800/200 mg). Data present as mean \pm SD.

Figure 2 The prediction of chloroquine concentration-time profiles in combination with 400/100 mg LPV/r given twice daily for 14 consecutive days. Data present as mean \pm SD.

Figure 3 The prediction of chloroquine concentration-time profiles in combination with 800/200 mg LPV/r given once daily for 14 consecutive days. Data present as mean $\pm \mathrm{SD}$.

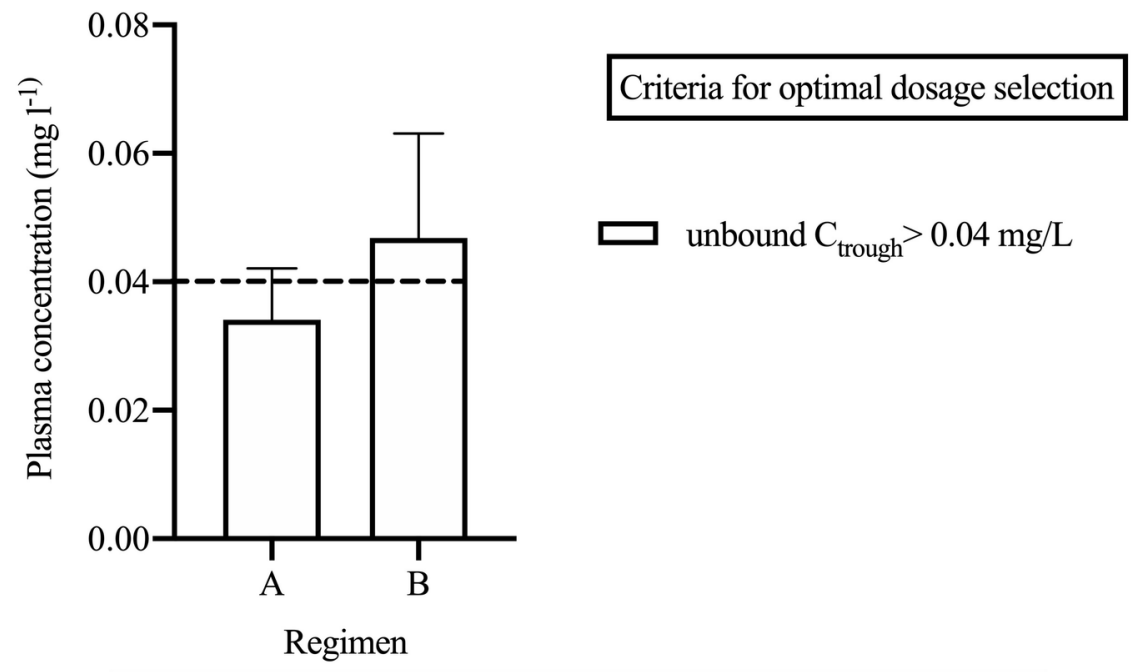

A: Lopinavir/ritonavir (400/100 mg) q $12 \mathrm{~h}$ for 14 consecutive days

B: Lopinavir/ritonavir (800/200 mg) q 24h for 14 consecutive days

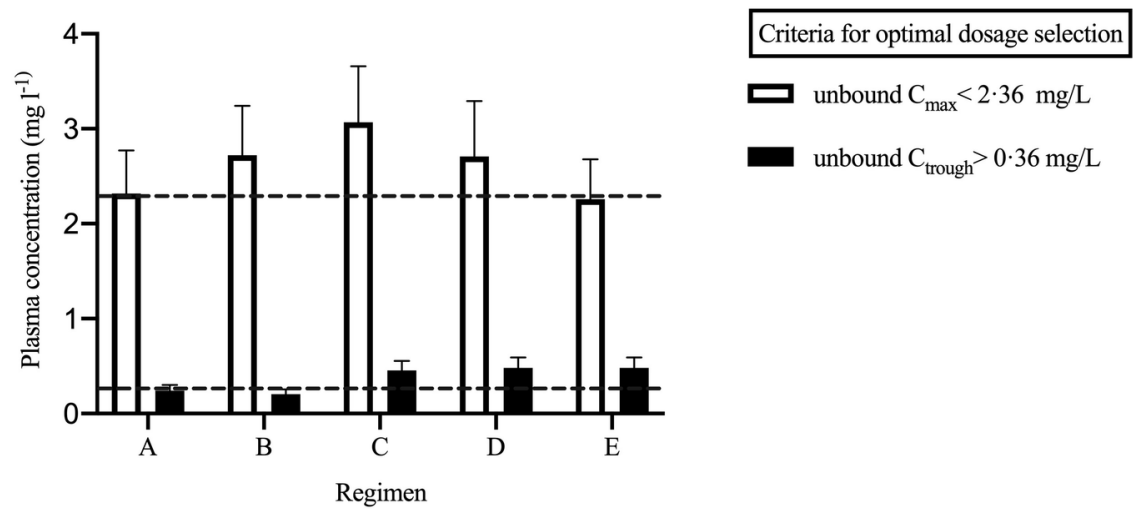

\footnotetext{
A: $500 \mathrm{mg} \mathrm{q} 12 \mathrm{~h}$ for 14 consecutive days

B: $400 \mathrm{mg} \mathrm{q} 8 \mathrm{~h}$ for 14 consecutive days

C: $1000 \mathrm{mg} \mathrm{q} 24 \mathrm{~h}$ for 14 consecutive days

D: A loading dose of $1000 \mathrm{mg}$, followed by $500 \mathrm{mg} \mathrm{q} 12 \mathrm{~h}$ on day 2 for 14 consecutive days

$\mathrm{E}$ : A loading dose of $1000 \mathrm{mg}$, followed by $500 \mathrm{mg} \mathrm{q} 12 \mathrm{~h}$ on day 2 for 8 doses,
}

followed by $400 \mathrm{mg} \mathrm{q} 12 \mathrm{~h}$ for 18 doses. 


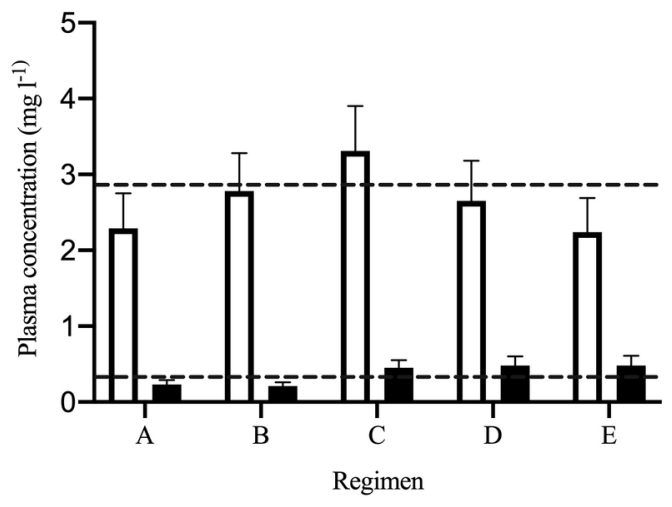

Criteria for optimal dosage selection

$\square$ unbound $\mathrm{C}_{\max }<2.36 \mathrm{mg} / \mathrm{L}$

unbound $C_{\text {trough }}>0.36 \mathrm{mg} / \mathrm{L}$

A: $500 \mathrm{mg} \mathrm{q} 12 \mathrm{~h}$ for 14 consecutive days

B: $400 \mathrm{mg} \mathrm{q} 8 \mathrm{~h}$ for 14 consecutive days

C: $1000 \mathrm{mg} \mathrm{q} 24 \mathrm{~h}$ for 14 consecutive days

D: A loading dose of $1000 \mathrm{mg}$, followed by $500 \mathrm{mg} \mathrm{q} 12 \mathrm{~h}$ on day 2 for 14 consecutive days

E: A loading dose of $1000 \mathrm{mg}$, followed by $500 \mathrm{mg} \mathrm{q} 12 \mathrm{~h}$ on day 2 for 8 doses,

followed by $400 \mathrm{mg} \mathrm{q} 12 \mathrm{~h}$ for 18 doses. 